\title{
The Effect of Exercise on Balance Function of Patients with Type 2 Diabetes
}

\author{
Cuixiao Wang, Lenan Cai, Meina Qiao, Shao Chen \& Yueqing $\mathrm{Xu}^{*}$ \\ Nursing College of Hebei University, Baoding, Hebei 071000, China
}

\begin{abstract}
Objective: The objective of the study is to evaluate the effects of exercise on balance function with people who have Type 2 diabetes. Methods: The subjects in the study were 26 patients with Type 2 diabetes exercise regularly and 27 patients with Type 2 diabetes who do not exercise. The two groups were compared based on the following: the fall index (FI), the low frequency of Fourier transformation (F1, F2) under natural standing on solid surface with eyes opened,the frequency of Fourier transformation (F1, F2, F5, F6) under Standing on the soft mat with eyes opened (PO), the high frequency of Fourier transformation (F5, F6) under natural standing on solid surface with eyes closed (NC), the frequency of Fourier transformation (F3, F4) under natural standing on solid surface with eyes closed and head turn to right(HR). Results: The fall index (FI), the frequency of Fourier transformation (F1, F5, F6) under Standing on the soft mat with eyes opened (PO) , the high frequency of Fourier transformation (F6) under natural standing on solid surface with eyes closed (NC) were statistically different for the two groups. The other parameters have no significant differences. The balance function of patients who exercise regularly were better than those who don't exercise.
\end{abstract}

\section{KEYWORDS}

Exercise

Balance

Type 2 diabetes

\section{Introduction}

In 2013 the number of patients with diabetes was 382 million around the world, and according to statistics, this number will reach 552 million in 2030 [1,2]. About 40\% of thepatients come from China and India. More than half of the patients over 60 years old also have complication with peripheral neuropathy, which displays symptoms such as lower limb muscle abate, paresthesia, pain, numbness and gait instability. Thisresults in a decline in motor function and thus balance function is impaired. Diabetic nephropathy and retinal change, due to the changes in visual and pathological invasion and each part of the nervous system, can make the lower limbs receive the wrong body sensory information caused by unstability and

Copyright (C) 2016 Yueqing Xu et al.

doi: 10.18686/jn.v5i1.1

This is an open-access article distributed under the terms of the Creative Commons Attribution Unported License (http://creativecommons.org/ licenses/by-nc/4.0/), which permits unrestricted use, distribution, and reproduction in any medium, provided the original work is properly cited.

*Corresponding author: Nursing College of Hebei University, Baoding, Hebei 071000, China. E-mail: yeqing160@163.com gait disturbance, therefore increasing risk of fall with diabetes patients $[3,4]$. Studies have pointed out thatfor people with diabetes who have complication with peripheral neuropathy, the prevalance of fall was five times more than healthy people of the same age, and more than half of the patients at least fall once a year due to the weakened balance function[3]. According to Health Ministry survey statistics, the elderlys' injury medical costs due to falling presents an increasing trend year by year in our country [5]. The study carried out by King found that $39.8 \%$ of elderly falls showed different degrees of decline in static balance function and the dynamic balance test prolonged reaction time, And as human conduct nerve and the trend of central integration capability significantly decline with increased age, balance function decline is the main reason for the elderly falls [6].

Exercise in patients with Type 2 diabetes has an important position; the 2013 edition of Type 2 diabetes prevention and treatment guidelines have pointed out that adult patients with Type 2 diabetes should do more than 150 minutes per week of moderate intensity of aerobic exercise, even if only one exercise is beneficial to the body [7]. The purpose of this study is to evaluate the effects of exercise on balance function 
with people who had Type 2 diabetes, provide quantitative data to reflect the benefits of exercise in order to improve the balance function of patients with Type 2 diabetes, and provide some reference to reduce the incidence of falls.

\section{Materials and methods}

The study was carried out on a group of people with Type 2 diabetes, hospitalized in the Endocrinology department in The First Central Hospital of Baoding city. The study was performed from February to March 2016. The subjects volunteered to participate in this study, meeting ADA 2010 diagnostic criteria. There were 53 patients with Type 2 diabetes $(28$ males and 25 females), at $56.04 \pm 9.85$ years of age, course of disease is $56.04 \pm 6.67$ years.

Inclusion criteria are: 1) meet the diagnosis of diabetes mellitus in patients with Type 2 diabetes; 2 ) lower limbs can continuous walk on the ground for 3 minutes without help, not fewer than 30 steps; 3 ) no cognitive impairment and mental illness; 4) informed consent to participate in research.

Exclusion criteria are: 1) Type 2 diabetes; 2) foot ulcers, gestational diabetes mellitus or other acute complications;

3) foot deformity caused by diabetes coexist with gout; 4) diabetes and abnormal gait is obvious after a stroke; 5) severe cardiopulmonary function disorder; 6) strict attention to blurred, need to walk or use the help line of auxiliary equipment of others.

The 53 subjects are divided into two groups, the exercise group and the contrast group. People in the contrast group only had the daily work life without additional sports exercise, while people in the exercise group, in addition to daily life work, also exercise for 4 to 7 times a week, with a duration of 30-90 minutes. Seven of them went for a brisk walk, 5 to 7 times a week, and 60 minutes each time; 2 people took up swimming and badminton, 4 times a week, every 60 to 90 minutes; 5 people took up setting-up exercise movement, 5 to 7 times a week, 40 to 60 minutes every time; 6 people took up tai chi, 7 times a week, and 75 minutes including warm-up and every movement ; 6 people went for bicycle exercise, 6 to 7 times a week, every 30 to 60 minutes.

The 2013 edition of Type 2 diabetes prevention and treatment guidelines points out that badminton, tai chi, brisk walks and riding a bicycle belong to medium intensity exercise, while swimming and setting-up exercise intensity belong to strong intensity exercise [7]. General data comparison between the two groups have no difference, as shown in Table 1.

Balance measurement using Israel Sunlight Tetrax balance testing system of medical equipment company. The Tetrax balance test system has four independent test platforms. The subjects were measured both first half part and the rest part of their feet with vertical pressure changes, and through the pressure sensor, automatic analysis of mechanical signals
Table 1. General data comparison of two groups.

\begin{tabular}{|c|c|c|c|c|}
\hline Factors & $\begin{array}{l}\text { Exercise } \\
\text { group }\end{array}$ & $\begin{array}{l}\text { Contrast } \\
\text { group }\end{array}$ & 1 & \\
\hline \multirow{2}{*}{ Gender } & $\begin{array}{l}\text { Male } 15 \\
(57.7 \%)\end{array}$ & $\begin{array}{l}\text { Male } 13 \\
(48.1 \%)\end{array}$ & \multirow{2}{*}{$x^{2}=0.484$} & \multirow{2}{*}{0.586} \\
\hline & $\begin{array}{l}\text { Female } 11 \\
(42.3 \%)\end{array}$ & $\begin{array}{c}\text { Female } 14 \\
(51.9 \%)\end{array}$ & & \\
\hline Age & $52.81 \pm 9.21$ & $59.15 \pm 9.59$ & $t=2.453$ & 0.923 \\
\hline Education & & & \multirow{6}{*}{$x^{2}=3.605$} & \multirow{6}{*}{0.462} \\
\hline Primary school & $4(15.4 \%)$ & 7 (25.9\%) & & \\
\hline $\begin{array}{l}\text { Junior high } \\
\text { school }\end{array}$ & 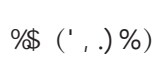 & 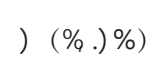 & & \\
\hline $\begin{array}{l}\text { High school or } \\
\text { technical } \\
\text { secondary school }\end{array}$ & 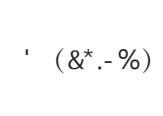 & 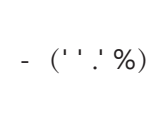 & & \\
\hline Junior college & 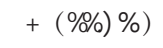 & 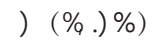 & & \\
\hline $\begin{array}{c}\text { Bachelor degree } \\
\text { or above }\end{array}$ & ५ (口.๑\%) & ८ (५.๑\%) & & \\
\hline Course of disease & $8.56 \pm 6.05$ & $9.72 \pm 7.29$ & $t=0.628$ & 0.665 \\
\hline
\end{tabular}

Diabetic complication

\begin{tabular}{|c|c|c|c|c|}
\hline No & $10(38.5 \%)$ & $10(37.0 \%)$ & \multirow{3}{*}{$x^{2}=3.900$} & \multirow{3}{*}{0.272} \\
\hline One type & (42.3\%) & 7 (25.9\%) & & \\
\hline Two types & $4(15.4 \%)$ & $5(18.5 \%)$ & & \\
\hline Three types & 1 (3.8\%) & 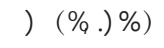 & & \\
\hline
\end{tabular}

Other chronic disease

\begin{tabular}{|c|c|c|c|c|}
\hline No & $3(11.5 \%)$ & $6(22.2 \%)$ & \multirow{4}{*}{$x^{2}=6.999$} & \multirow{4}{*}{0.072} \\
\hline One type & $\square 3(50.0 \%)$ & $5(18.5 \%)$ & & \\
\hline Two types & $8(30.8 \%)$ & $10(37.0 \%)$ & & \\
\hline $\begin{array}{c}\text { Three types } \\
\text { or more }\end{array}$ & $2(7.7 \%)$ & $6(22.2 \%)$ & & \\
\hline
\end{tabular}

Whether added

calcium supplements

\begin{tabular}{lrrrr}
\hline Yes & $9(34.6 \%)$ & $9(33.3 \%)$ & $\chi^{2}=0.010$ & 1.000 \\
No & $77(65.4 \%)$ & $18(66.7 \%)$ & & \\
\hline
\end{tabular}

Whether added aspirin

$\begin{array}{lllll}\text { Yes } & 10(38.5 \%) & 9(29.6 \%)\end{array} \quad \chi^{2}=0.461 \quad 0.569$

Note: $p<0.05$ was regarded as statistically significant.

into the computer processing.

Test subjects were quiet standing in Tetrax test force platform, on the front and the rear feet on the A, B, C, D four test tablets. They portrayed eight kinds of postures(standing under normal condition with eyes opened; standing under normal condition with eyes closed; standing on the soft mat with eyes opened; standing on the soft mat with eyes closed; head to the left with eyes closed; head leaned back with eyes closed; low head forward with 
eyes closed) of general Stability (Stability Index, ST), Fourier transform (F1-F8), the weight distribution Index (WDI), heel and toe part pressure model of synchronicity. To fully explain the purpose and the matters needing attention to the participants before the testing, an appropriate indoor temperature and humidityare kept together with a quiet environment to guarantee the subjects without interference.

The parameters studied were: the Fourier transform F1 and F2 under the posture which stand under normal condition with eyes opened (NO), the Fourier transform F5 and F6 under the posture which stand under normal condition with eyes closed (NC), the Fourier transform of F1, F2, F5 and F6 under the posture which standing on the soft mat with eyes opened (PO),the Fourier transform F3 and F4 under the posture which head to the right with eyes closed (HR), and the fall index (FI), which is computed based on eight kinds of all parameters of the position and automatically generated data index analysis.

After double entry data, using spss 20.0 software for statistical analysis, count data using percentage expression, measurement data using mean standard deviation expression. Measurement data of two independent sample mean use independent sample $t$-test, count data using chisquare test. $p<0.0 .5$ was regarded as statistically significant.

\section{Results}

The exercise group and the contrast group compared the balance function, the fall index (FI), the frequency of Fourier transformation (F1,F5,F6) under Standing on the soft mat with eyes opened (PO), the high frequency of Fourier transformation (F6) under natural standing on solid surface with eyes closed (NC) of two groups were statistically different. Under the posture of normally standing with eyes opened (NO) the Fourier transform F1,F2, the Fourier transform F5 under normally standing with eyes closed (NC), the Fourier transform of F2 under standing on the soft mat with eyes opened (PO),the Fourier transform F3 and F4

Table 2. Comparison of the balance parameters between the two groups of patients.

\begin{tabular}{lcccc}
\hline & Exercise group & Contrast group & $t\left(t^{\prime}\right)$ & $p$ \\
\hline Fall index & $32.96 \pm 16.35$ & $52.81 \pm 27.27$ & 3.199 & 0.002 \\
NO F1 & $17.29 \pm 7.18$ & $20.21 \pm 8.50$ & 1.345 & 0.185 \\
NO F2 & $13.57 \pm 5.74$ & $15.66 \pm 5.59$ & 1.342 & 0.185 \\
NC F5 & $4.08 \pm 1.29$ & $5.09 \pm 2.67$ & 1.746 & 0.087 \\
NC F6 & $2.87 \pm 1.32$ & $4.03 \pm 2.06$ & 2.427 & 0.019 \\
PO F1 & $18.38 \pm 10.42$ & $27.25 \pm 16.21$ & 2.359 & 0.022 \\
PO F2 & $14.43 \pm 6.01$ & $18.69 \pm 10.24$ & 1.835 & 0.072 \\
PO F5 & $3.98 \pm 1.35$ & $5.42 \pm 2.33$ & 2.720 & 0.009 \\
PO F6 & $2.79 \pm 1.02$ & $4.03 \pm 2.26$ & 2.536 & 0.014 \\
HR F3 & $8.54 \pm 3.24$ & $10.02 \pm 3.63$ & 1.566 & 0.124 \\
HR F4 & $7.00 \pm 2.30$ & $8.76 \pm 4.24$ & 1.869 & 0.067 \\
\hline
\end{tabular}

Note: $p<0.05$ was regarded as statistically significant. under head to the right stand with eyes closed (HR),there is no significant difference between the exercise group and the contrast group (Table 2).

\section{Discussion}

In the balance evaluation of subjects, the balance function of patients with Type 2 diabetes doing exercise was superior to the contrast group with Type 2 diabetes and do not exercise. Fall index is the algorithm of computer use patent according to Tetrax test results and calculates subjects fall risk value, whichhas nothing to do with the height and weight of the subjects.

Comparing the exercise group of patients with the contrast group, the fall index has significant difference ( $p=$ 0.002 ); the group of patients with exercise compared with patients who do not exercise show a strong ability of balance. The better the balance function, the lesser the risk of falls less. Fall index fall in the range from 0-100 with 0 denoting no risk and 100 denoting the most likely to fall. The study showed that the fall in the contrast group (52.81 \pm 27.27 ) index is higher and thus the risk of falls is larger. The direct and indirect effects caused by falling damage will bring huge economic burden to family and the society, and also bring mental pressure to patients and their families [8].

Two groups of patients under the posture standing on the soft mat with eyes opened (PO) of Fourier transformation F5 ( $p=0.009)$, F6 $(p=0.014)$ and under normal standing close their eyes (NC) position of Fourier transform F6 ( $p=$ 0.019) have significant difference, the high frequency oscillation frequency posture abnormal F5, F6 prompt ontology paresthesia, show that two groups of patients have significant differences of proprioception. Two groups of patients in the normal standing head to the right and close their eyes (HR), under this posture of Fourier transform F3 $(p=0.124)$, the F4 $(p=0.067)$ there was no significant difference, low frequency oscillation frequency F3 and F4 abnormal will be prompted vestibular function paresthesia, show that comparing the two groups of patients, there was no significant difference in the feel of vestibular function. Low frequency oscillation frequency posture F1 and F2 can prompt visual anomaly, two groups of patients standing on the soft mat with eyes opened (PO), under the posture of the Fourier transform of F1 $(p=0.022)$, prompted two groups of patients with visual has significant difference under the posture, Fourier transformation under the normal open posture F1 $(p=0.185)$ and F2 $(p=0.185)$, prompted two groups of patients under these postures of visual there was no significant difference.

Vision and proprioception, vestibular together afferent signals to the central nervous system, whichthen issues instructions to adjust the human body to keep balance. Proprioception is a deep feeling, proprioception receiver is located in the joints, muscles and tendons, more studies have pointed out that there are a lot of proprioception receiver in the muscles around the joint which has important clinical 
effect in joint control, adjust the body posture and balance [8]. Studies have proved that patients with diabetes peripheral neuropathy for the training the muscle around ankle, through to promote the ontology sense, the function of balance will have significantly improved [9]. In this study, the proprioception of patients who belong to exercise group is obviously better than the contrast group patients. This prompts the positive role of the exercise to proprioception, research has shown wuqinxi and taiji can improve muscle strength, posture stability, joint mobility, proprioception and neuromuscular reflex ability [10,11], and 2013 edition of Type 2 diabetes prevention and treatment guidelines also pointed out that exercise therapy plays an important role in the prevention and control Type 2 diabetes. When the balance function of patients with diabetes is damaged, the risk of falls becomes higher than others, thus the problem of falling down due to balance disorder should be our concern. To prevent people falling down in treatment or at work, clinical personnel can be targeted to provide training, such as toes training and taiji exerciseto improve the patients' balance function. This study has proved that the benefits of exercise on the balance function of patients with Type 2 diabetes. Whileatients are in treatment or at work, they can, according to one's own circumstance, do some moderate exercise, to improve one's balance function and reduce the incidence of falls.

\section{Conclusion}

The balance function of patients with Type 2 diabetes do exercise was superior to the contrast group who have Type 2 diabetes and do not exercise. This study has some deficiency as the study sample size is small. It is hard to avoid some bias as after age 50 human balance function will decline along with the age increase [12], and some of the subjects of this study are middle-aged patients. The balance problem of old people should require more attention and in future research, the older population sample size should be increased. Balance ability decline caused by falling problem has become a hotspot in current researches, and the number of patients with diabetes in our country population is so large such that balance function disorder in patients with diabetes and the resulting problems are worth our attention and research.

\section{References}

1. Sicree R, Shaw J, Zimmet P. Executive Summary. In: Gan D, ed. Diabetes Atlas, 2nd edn. Brussels: International Diabetes Federation and World Diabetes Foundation, 2003.

2. International Diabetes Federation. Diabetes Atlas. 6th ed. Available at: http://www.idf.org/diabetesatlas/. Accessed on: April 8, 2014.

3. Brown SJ, Handsaker JC, Bowling FL, Boulton AJ, Reeves ND. Diabetic peripheral neuropathy compromises balance during daily activities. Diabetes Care. 2015;38(6):11161122.

4. Trujillo AJ, Hyder AA, Steinhardt LC. Cognitive functioning and the probability of falls among seniors in Havana, Cuba. International Journal of Aging and Human Development. 2011;73(2):175-194.

5. Huang $\mathrm{CL}$. The influence of population aging on growth of health expenditure. Chinese Journal of Population Science. 2004;4:36-43.

6. King EC, McKay SM, Cheng KC, Maki BE. The use of peripheral vision to guide perturbation-evoked reach-tograsp balance-recovery reactions. Experimental Brain Research. 2010;207(1-2):105-118.

7. 2013 edition of type 2 diabetes prevention and treatment guidelines.

8. Ordway NR, Hand N, Briggs G, Ploutz-Synder LL. Reliability of knee and ankle strength measures in an older adult population. Journal of Strength and Conditioning Research. 2006;20(1):82-87.

9. Boss C, Manor B, Li L. Selected function performance in healthy young and old, as well as people with peripheral neuropathy. Medicine \& Science in Sports \& Exercise. 2008;40(5):S88.

10. Xu DQ, Li JX, Hong Y. Effects of long term Tai Chi practice and jogging exercise on muscle strength and endurance in older people. British Journal of Sports Medicine. 2006;40(1):50-54.

11. Gong ZK, Zhai HW, Chen W, et al. Effects of proprioception strengthening training on knee osteoarthritis. Chinese Journal of Rehabilitation Theory and Practice. 2010;16(2).

12. Larson L, Bergmann TF. Taking on the fall: the etiology and prevention of falls in the elderly. Clinical Chiropractic. 2008;11(3):148-154. 